\title{
Existence and Algorithm for the Systems of Hierarchical Variational Inclusion Problems
}

\author{
Nopparat Wairojjana ${ }^{1,2}$ and Poom Kumam² \\ ${ }^{1}$ Faculty of Science and Technology, Valaya Alongkorn Rajabhat University under the Royal Patronage, 1 Phaholyothin Road, \\ Klong Nueng, Klong Luang, Pathumthani 13180, Thailand \\ ${ }^{2}$ Department of Mathematics, Faculty of Science, King Mongkut's University of Technology Thonburi (KMUTT), \\ 126 Pracha Uthit Road, Bang Mod, Thrung Khru, Bangkok 10140, Thailand
}

Correspondence should be addressed to Poom Kumam; poom.kum@kmutt.ac.th

Received 18 May 2014; Revised 3 September 2014; Accepted 4 September 2014; Published 23 December 2014

Academic Editor: Juan R. Torregrosa

Copyright (c) 2014 N. Wairojjana and P. Kumam. This is an open access article distributed under the Creative Commons Attribution License, which permits unrestricted use, distribution, and reproduction in any medium, provided the original work is properly cited.

We study the existence and approximation of a solution for a system of hierarchical variational inclusion problems in Hilbert spaces. In this study, we use Maingé's approach for finding the solutions of the system of hierarchical variational inclusion problems. Our result in this paper improves and generalizes some known corresponding results in the literature.

\section{Introduction}

Let $H$ be a real Hilbert space with inner product and norm being $\langle\cdot, \cdot\rangle$ and $\|\cdot\|$, respectively, and let $C$ be a nonempty closed convex subset of $H$. A mapping $T: H \rightarrow H$ is called nonexpansive if

$$
\|T x-T y\| \leq\|x-y\|, \quad \forall x, y \in H .
$$

We use $F(T)$ to denote the set of fixed points of $T$; that is, $F(T)=\{x \in H: T x=x\}$. It is well known that $F(T)$ is a closed convex set, if $T$ is nonexpansive mappings.

A variational inclusion problem [1-3] is the problem of finding a point $u \in H$ such that

$$
\theta \in A(u)+M(u)
$$

where $A: H \rightarrow H$ is a single-valued nonlinear mapping and $M: H \rightarrow 2^{H}$ is a multivalued mapping. We use $\Omega$ to denote the set of solutions of the variational inclusion (2).

On the other hand, a hierarchical fixed point problem [4$11]$ is the problem of finding a point $x^{*} \in F(T)$ such that

$$
\left\langle A x^{*}, x-x^{*}\right\rangle \geq 0, \quad \forall x \in F(T) .
$$

If the set $F(T)$ is replaced by the solution set of the variational inequality, then the hierarchical fixed point problems are called hierarchical variational inequality problems or hierarchical optimization problems. Many problems in mathematics, for example, the signal recovery [12], the power control problem [13], and the beamforming problem [14], can be considered in the framework of this kind of the hierarchical variational inequality problems.

Recently, Chang et al. [15] introduced bilevel hierarchical variational inclusion problems; that is, find $\left(x^{*}, y^{*}\right) \in \Omega_{1} \times$ $\Omega_{2}$ such that, for given positive real numbers $\rho$ and $\eta$, the following inequalities hold:

$$
\begin{aligned}
& \left\langle\rho F\left(y^{*}\right)+x^{*}-y^{*}, x-x^{*}\right\rangle \geq 0, \quad \forall x \in \Omega_{1}, \\
& \left\langle\eta F\left(x^{*}\right)+y^{*}-x^{*}, y-y^{*}\right\rangle \geq 0, \quad \forall y \in \Omega_{2},
\end{aligned}
$$

where $F, A_{1}, A_{2}: H \rightarrow H$ are mappings, $M_{1}, M_{2}: H \rightarrow 2^{H}$ are multivalued mappings, and $\Omega_{i}$ is the set of solutions to variational inclusion problem (2) with $A=A_{i}, M=M_{i}$ for $i=1,2$. They solved the convex programming problems and quadratic minimization problems by using Maingés scheme. 
In this paper, we consider the following system of hierarchical variational inclusion problem: find $\left(x^{*}, y^{*}, z^{*}\right) \in \Omega_{1} \times$ $\Omega_{2} \times \Omega_{3}$, such that, for given positive real numbers $\rho, \eta$, and $\xi$, the following inequalities hold:

$$
\begin{array}{ll}
\left\langle\rho F\left(y^{*}\right)+x^{*}-y^{*}, x-x^{*}\right\rangle \geq 0, & \forall x \in \Omega_{1}, \\
\left\langle\eta F\left(z^{*}\right)+y^{*}-z^{*}, y-y^{*}\right\rangle \geq 0, & \forall y \in \Omega_{2}, \\
\left\langle\xi F\left(x^{*}\right)+z^{*}-x^{*}, z-z^{*}\right\rangle \geq 0, & \forall z \in \Omega_{3} .
\end{array}
$$

Some special cases of the system of hierarchical variational inclusion problem (5) are as follows.

(I) If $M_{i}=0, A_{i}=I-T_{i}$, where $T_{i}: H \rightarrow H$ is a nonlinear mapping for each $i=1,2,3$, in (5), then $\Omega_{i}=$ $F\left(T_{i}\right)$ and the system of hierarchical variational inclusion problem (5) reduces to the following system of hierarchical optimization problem: find $\left(x^{*}, y^{*}, z^{*}\right) \in$ $F\left(T_{1}\right) \times F\left(T_{2}\right) \times F\left(T_{3}\right)$, such that

$$
\begin{array}{ll}
\left\langle\rho F\left(y^{*}\right)+x^{*}-y^{*}, x-x^{*}\right\rangle \geq 0, & \forall x \in F\left(T_{1}\right), \\
\left\langle\eta F\left(z^{*}\right)+y^{*}-z^{*}, y-y^{*}\right\rangle \geq 0, & \forall y \in F\left(T_{2}\right), \\
\left\langle\xi F\left(x^{*}\right)+z^{*}-x^{*}, z-z^{*}\right\rangle \geq 0, & \forall z \in F\left(T_{3}\right),
\end{array}
$$

which was studied by Li [16].

(II) If $T_{i}=P_{K_{i}}$ for each $i=1,2,3$, where $P_{K_{i}}$ is the metric projection from $H$ onto a nonempty closed convex subset $K_{i}$ in (6), then it is clear that the $\Omega_{i}=F\left(T_{i}\right)=K_{i}$ and the system of hierarchical optimization problem (6) reduces to the following system of optimization problem: find $\left(x^{*}, y^{*}, z^{*}\right) \in$ $K_{1} \times K_{2} \times K_{3}$ such that

$$
\begin{array}{ll}
\left\langle\rho F\left(y^{*}\right)+x^{*}-y^{*}, x-x^{*}\right\rangle \geq 0, & \forall x \in K_{1}, \\
\left\langle\eta F\left(z^{*}\right)+y^{*}-z^{*}, y-y^{*}\right\rangle \geq 0, & \forall y \in K_{2}, \\
\left\langle\xi F\left(x^{*}\right)+z^{*}-x^{*}, z-z^{*}\right\rangle \geq 0, & \forall z \in K_{3} .
\end{array}
$$

(III) If $K_{1}=K_{2}=K_{3}$, then the system of optimization problem (7) reduces to the following system of variational inequality problem: find $\left(x^{*}, y^{*}, z^{*}\right) \in K_{1} \times K_{1} \times$ $K_{1}$ such that

$$
\begin{array}{ll}
\left\langle\rho F\left(y^{*}\right)+x^{*}-y^{*}, x-x^{*}\right\rangle \geq 0, & \forall x \in K_{1}, \\
\left\langle\eta F\left(z^{*}\right)+y^{*}-z^{*}, y-y^{*}\right\rangle \geq 0, & \forall y \in K_{1}, \\
\left\langle\xi F\left(x^{*}\right)+z^{*}-x^{*}, z-z^{*}\right\rangle \geq 0, & \forall z \in K_{1} .
\end{array}
$$

(IV) If $\xi=0, \rho, \eta>0, \Omega_{1}=\Omega_{3}$, and $x^{*}=z^{*}$ in (5) then the system of hierarchical variational inclusion problem (5) reduces to the following bilevel hierarchical variational inclusion problem: find $\left(x^{*}, y^{*}\right) \in \Omega_{1} \times \Omega_{2}$ such that

$$
\begin{array}{ll}
\left\langle\rho F\left(y^{*}\right)+x^{*}-y^{*}, x-x^{*}\right\rangle \geq 0, & \forall x \in \Omega_{1}, \\
\left\langle\eta F\left(x^{*}\right)+y^{*}-x^{*}, y-y^{*}\right\rangle \geq 0, & \forall y \in \Omega_{2},
\end{array}
$$

which was studied by Chang et al. [15].
(V) In (9), if $M_{i}=0, A_{i}=I-T_{i}$, for each $i=1,2$, then bilevel hierarchical variational inclusion problem (9) reduces to the following bilevel hierarchical optimization problem: find $\left(x^{*}, y^{*}\right) \in F\left(T_{1}\right) \times F\left(T_{2}\right)$ such that

$$
\begin{aligned}
& \left\langle\rho F\left(y^{*}\right)+x^{*}-y^{*}, x-x^{*}\right\rangle \geq 0, \quad \forall x \in F\left(T_{1}\right), \\
& \left\langle\eta F\left(x^{*}\right)+y^{*}-x^{*}, y-y^{*}\right\rangle \geq 0, \quad \forall y \in F\left(T_{2}\right),
\end{aligned}
$$

which was studied by Maingé [17] and Kraikaew and Saejung [18].

(VI) In (10), if $T_{i}=P_{K_{i}}$ for each $i=1,2$, then bilevel hierarchical optimization problem (10) reduces to the following problem [19-21]: find $\left(x^{*}, y^{*}\right) \in K_{1} \times K_{2}$ such that

$$
\begin{aligned}
& \left\langle\rho F\left(y^{*}\right)+x^{*}-y^{*}, x-x^{*}\right\rangle \geq 0, \quad \forall x \in K_{1}, \\
& \left\langle\eta F\left(x^{*}\right)+y^{*}-x^{*}, y-y^{*}\right\rangle \geq 0, \quad \forall y \in K_{2} .
\end{aligned}
$$

(VII) In (11), if $K_{1}=K_{2}$ then the problem (11) reduces to the following problem: find $\left(x^{*}, y^{*}\right) \in K_{1} \times K_{1}$ such that

$$
\begin{aligned}
& \left\langle\rho F\left(y^{*}\right)+x^{*}-y^{*}, x-x^{*}\right\rangle \geq 0, \quad \forall x \in K_{1}, \\
& \left\langle\eta F\left(x^{*}\right)+y^{*}-x^{*}, y-y^{*}\right\rangle \geq 0, \quad \forall y \in K_{1} .
\end{aligned}
$$

(VIII) In (5), if $\xi=\eta=0, \rho>0, \Omega_{1}=\Omega_{2}=\Omega_{3}$, and $x^{*}=y^{*}=z^{*}$ then the system of hierarchical variational inclusion problem (5) reduces to the following hierarchical variational inclusion problem: find $x^{*} \in \Omega_{1}$ such that

$$
\left\langle F\left(y^{*}\right), x-x^{*}\right\rangle \geq 0, \quad \forall x \in \Omega_{1} .
$$

(IX) In (13), if $M_{1}=0, A_{i}=I-T_{1}$ then the hierarchical variational inclusion problem (13) reduces to the following hierarchical fixed point problem: find $x^{*} \in$ $F\left(T_{1}\right)$ such that

$$
\left\langle F\left(y^{*}\right), x-x^{*}\right\rangle \geq 0, \quad \forall x \in F\left(T_{1}\right) .
$$

(X) In (15), if $T_{1}=P_{K_{1}}$ then the hierarchical fixed point problem (15) reduces to the following classic variational inequality problem: find $x^{*} \in K_{1}$ such that

$$
\left\langle F\left(y^{*}\right), x-x^{*}\right\rangle \geq 0, \quad \forall x \in K_{1} .
$$

Motivated and inspired by Chang et al. [15], we introduce the system of a hierarchical variational inclusion problem (5) and investigate a more general variant of the scheme proposed by Chang et al. [15] to solve the system of a hierarchical variational inclusion problem. Our analysis and method allow us to prove the existence and approximation of solutions to the system of a hierarchical variational inclusion problem (5). The results presented in this paper extend and improve the results of Chang et al. [15], Maingé [17], Kraikaew and Saejung [18], and some authors. 


\section{Preliminaries}

This section collects some definitions and lemmas which can be used in the proofs for the main results in the next section. Some of them are known; others are not hard to derive. We use $\rightarrow$ for strong convergence and $\rightarrow$ for weak convergence.

Definition 1. Let $A, T, F: H \rightarrow H$ be a mapping and let $M: H \rightarrow 2^{H}$ be a multivalued mapping.

(1) A mapping $T$ is called nonexpansive if

$$
\|T x-T y\| \leq\|x-y\|, \quad \forall x, y \in H .
$$

(2) A mapping $T$ is called quasinonexpansive if $F(T) \neq \emptyset$ and

$$
\|T x-p\| \leq\|x-p\|, \quad \forall x \in H, p \in F(T) .
$$

It should be noted that $T$ is quasinonexpansive if and only if for all $x \in H, p \in F(T)$

$$
\langle x-T x, x-p\rangle \geq \frac{1}{2}\|x-T x\|^{2} \text {. }
$$

(3) A mapping $T$ is called strongly quasinonexpansive if $T$ is quasinonexpansive and $x_{n}-T x_{n} \rightarrow 0$, whenever $\left\{x_{n}\right\}$ is a bounded sequence in $H$ and $\left\|x_{n}-p\right\|-\| T x_{n}-$ $p \| \rightarrow 0$ for some $p \in F(T)$.

(4) A mapping $F$ is called $\mu$-Lipschitzian if there exists $\alpha>$ 0 such that

$$
\|F x-F y\| \leq \mu\|x-y\|, \quad \forall x, y \in H .
$$

(5) A mapping $F$ is called $r$-strongly monotone if there exists $r>0$ such that

$\langle F x-F y, x-y\rangle \geq r\|x-y\|^{2}, \quad \forall x, y \in H$.

It is easy to prove that if $F: H \rightarrow H$ is a $\mu$ Lipschitzian and $r$-strongly monotone mapping and if $\rho \in\left(0,2 r / \mu^{2}\right)$, then the mapping $I-\rho F$ is a contraction.

(6) A mapping $A$ is called $\alpha$-inverse-strongly monotone if there exists $\mu>0$ such that

$$
\langle A x-A y, x-y\rangle \geq \alpha\|A x-A y\|^{2}, \quad \forall x, y \in H .
$$

(7) A multivalued mapping $M$ is called monotone if for all $x, y \in H, u \in M x$ and $v \in M y$ imply that

$$
\langle u-v, x-y\rangle \geq 0 \text {. }
$$

(8) A multivalued mapping $M$ is called maximal monotone if it is monotone and for any $(x, u) \in H \times H$,

$$
\langle u-v, x-y\rangle \geq 0
$$

for every $(y, v) \in \operatorname{Graph}(M)$ (the graph of mapping $M$ ) implies that $u \in M x$.
Lemma 2 (see [22]). Let $A: H \rightarrow H$ be an $\alpha$-inverse-strongly monotone mapping. Then

(1) $A$ is an $1 / \alpha$-Lipschitz continuous and monotone mapping;

(2) for any constant $\lambda>0$, one has

$$
\begin{aligned}
& \|(I-\lambda A) x-(I-\lambda A) y\|^{2} \\
& \quad \leq\|x-y\|^{2}+\lambda(\lambda-2 \alpha)\|A x-A y\|^{2} ;
\end{aligned}
$$

(3) if $\lambda \in(0,2 \alpha]$, then $I-\lambda A$ is a nonexpansive mapping, where $I$ is the identity mapping on $H$.

Lemma 3. Let $x \in H$ and $z \in C$ be any points. Then one has the following.

(1) That $z=P_{C}[x]$ if and only if there holds the relation:

$$
\langle x-z, y-z\rangle \leq 0, \quad \forall y \in C \text {. }
$$

(2) That $z=P_{C}[x]$ if and only if there holds the relation:

$$
\|x-z\|^{2} \leq\|x-y\|^{2}-\|y-z\|^{2}, \quad \forall y \in C .
$$

(3) There holds the relation:

$$
\begin{array}{r}
\left\langle P_{C}[x]-P_{C}[y], x-y\right\rangle \geq\left\|P_{C}[x]-P_{C}[y]\right\|^{2}, \\
\forall x, y \in H .
\end{array}
$$

Consequently, $P_{C}$ is nonexpansive and monotone.

Definition 4. Let $M: H \rightarrow 2^{H}$ be a multivalued maximal monotone mapping. Then the mapping $J_{M, \lambda}: H \rightarrow H$ defined by

$$
J_{M, \lambda}(u)=(I+\lambda M)^{-1}(u), \quad u \in H
$$

is called the resolvent operator associated with $M$, where $\lambda$ is any positive number and $I$ is the identity mapping.

Proposition 5 (see [22]). Let $M: H \rightarrow 2^{H}$ be a multivalued maximal monotone mapping, and let $A: H \rightarrow H$ be an $\alpha$-inverse-strongly monotone mapping. Then the following conclusions hold.

(1) The resolvent operator $J_{M, \lambda}$ associated with $M$ is singlevalued and nonexpansive for all $\lambda>0$.

(2) The resolvent operator $J_{M, \lambda}$ is 1-inverse-strongly monotone; that is,

$$
\begin{array}{r}
\left\|J_{M, \lambda}(x)-J_{M, \lambda}(y)\right\|^{2} \leq\left\langle x-y, J_{M, \lambda}(x)-J_{M, \lambda}(y)\right\rangle, \\
\forall x, y \in H .
\end{array}
$$

(3) $u \in H$ is a solution of the variational inclusion (2) if and only if $u=J_{M, \lambda}(u-\lambda A u)$, for all $\lambda>0$; that is, $u$ is a fixed point of the mapping $J_{M, \lambda}(I-\lambda A)$. Therefore one has

$$
\Omega=F\left(J_{M, \lambda}(I-\lambda A)\right), \quad \forall \lambda>0,
$$


where $\Omega$ is the set of solutions of variational inclusion problem (2).

(4) If $\lambda \in(0,2 \alpha]$, then $\Omega$ is a closed convex subset in $H$.

Lemma 6 (see [23]). For $x, y \in H$ and $\omega \in(0,1)$, the following statements hold:

(1) $\|x+y\|^{2} \leq\|x\|^{2}+2\langle y, x+y\rangle ;$

(2) $\|(1-\omega) x+\omega y\|^{2}=(1-\omega)\|x\|^{2}+\omega\|y\|^{2}-\omega(1-\omega)\|x-y\|^{2}$.

Lemma 7 (see [24]). Let $\left\{a_{n}\right\}$ be a sequence of real numbers, and there exists a subsequence $\left\{a_{m_{j}}\right\}$ of $\left\{a_{n}\right\}$ such that $a_{m_{j}}<$ $a_{m_{j}+1}$ for all $j \in N$, where $N$ is the set of all positive integers. Then there exists a nondecreasing sequence $\left\{n_{k}\right\}$ of $N$ such that $\lim _{k \rightarrow \infty} n_{k}=\infty$ and the following properties are satisfied by all (sufficiently large) number $k \in N$ :

$$
a_{n_{k}} \leq a_{n_{k}+1}, \quad a_{k} \leq a_{n_{k}+1} .
$$

In fact, $n_{k}$ is the largest number $n$ in the set $\{1,2, \ldots, k\}$ such that $a_{n}<a_{n+1}$ holds.

Lemma 8 (see [18]). Let $\left\{a_{n}\right\} \subset[0, \infty),\left\{\alpha_{n}\right\} \subset[0,1),\left\{b_{n}\right\} \subset$ $(-\infty,+\infty)$, and $h \in[0,1)$ be such that

(1) $\left\{a_{n}\right\}$ is a bounded sequence;

(2) $a_{n+1} \leq\left(1-\alpha_{n}\right)^{2} a_{n}+2 \alpha_{n} h \sqrt{a_{n}} \sqrt{a_{n+1}}+\alpha_{n} b_{n}$, for all $n \geq 1$;

(3) whenever $\left\{a_{n_{k}}\right\}$ is a subsequence of $\left\{a_{n}\right\}$ satisfying

$$
\liminf _{k \rightarrow \infty}\left(a_{n_{k}+1}-a_{n_{k}}\right) \geq 0
$$

it follows that $\lim _{\sup _{k \rightarrow \infty}} b_{n_{k}} \leq 0$;

(4) $\lim _{n \rightarrow \infty} \alpha_{n}=0$ and $\sum_{n=1}^{\infty} \alpha_{n}=\infty$.

Then $\lim _{n \rightarrow \infty} a_{n}=0$.

Lemma 9 (see [15]). Let $M: H \rightarrow 2^{H}$ be a multivalued maximal monotone mapping, let $A: H \rightarrow H$ be an $\alpha$-inversestrongly monotone mapping, and let $\Omega$ be the set of solutions of variational inclusion problem (2) and $\Omega \neq \emptyset$. Then the following statements hold.

(1) If $\lambda \in(0,2 \alpha]$, then the mapping $K: H \rightarrow H$ defined by

$$
K:=J_{M, \lambda}(I-\lambda A)
$$

is quasinonexpansive, where $I$ is the identity mapping and $J_{M, \lambda}$ is the resolvent operator associated with $M$.

(2) The mapping $I-K: H \rightarrow H$ is demiclosed at zero; that is, for any sequence $\left\{x_{n}\right\} \subset H$, if $x_{n} \rightarrow x$ and $(I-K) x_{n} \rightarrow 0$, then $x=K x$.

(3) For any $\beta \in(0,1)$, the mapping $K_{\beta}$ defined by

$$
K_{\beta}=(1-\beta) I+\beta K
$$

is a strongly quasinonexpansive mapping and $F\left(K_{\beta}\right)=$ $F(K)$.

(4) $I-K_{\beta}, \beta \in(0,1)$ is demiclosed at zero.

\section{Main Results}

Throughout this section, we always assume that the following conditions are satisfied:

(C1) $M_{i}: H \rightarrow 2^{H}$ is a multivalued maximal monotone mapping, $A_{i}: H \rightarrow H$ is an $\alpha_{i}$-inverse-strongly monotone mapping, and $\Omega_{i}$ is the set of solutions to variational inclusion problem (2) with $A=A_{i}$, $M=M_{i}$, and $\Omega_{i} \neq \emptyset$, for all $i=1,2,3$;

(C2) $K_{i}$ and $K_{i, \beta}, \beta \in(0,1), i=1,2,3$, are the mappings defined by

$$
\begin{aligned}
& K_{i}:=J_{M_{i}, \lambda}\left(I-\lambda A_{i}\right), \quad \lambda \in\left(0,2 \alpha_{i}\right], \\
& K_{i, \beta}:=(1-\beta) I+\beta K_{i}, \quad \beta \in(0,1),
\end{aligned}
$$

respectively.

Next, there are our main results.

\subsection{An Existence Theorem}

Theorem 10. Let $A_{i}, M_{i}, \Omega_{i}, K_{i}$, and $K_{i, \beta}$ satisfy conditions (C1) and (C2), and let $f_{i}: H \rightarrow H$ be contractions with a contractive constant $h_{i} \in(0,1)$, for all $i=1,2,3$. Then there exists a unique element $\left(x^{*}, y^{*}, z^{*}\right) \in \Omega_{1} \times \Omega_{2} \times \Omega_{3}$ such that the following three inequalities are satisfied:

$$
\begin{array}{ll}
\left\langle x^{*}-f_{1}\left(y^{*}\right), x-x^{*}\right\rangle \geq 0, & \forall x \in \Omega_{1}, \\
\left\langle y^{*}-f_{2}\left(z^{*}\right), y-y^{*}\right\rangle \geq 0, & \forall y \in \Omega_{2}, \\
\left\langle z^{*}-f_{3}\left(x^{*}\right), z-z^{*}\right\rangle \geq 0, & \forall z \in \Omega_{3} .
\end{array}
$$

Proof. The proof is a consequence of Banach's contraction principle but it is given here for the sake of completeness. By Proposition 5 and Lemma $9, \Omega_{1}, \Omega_{2}$, and $\Omega_{3}$ are nonempty closed and convex. Therefore the metric projection $P_{\Omega_{i}}$ is well defined for each $i=1,2,3$.

Since $f_{i}$ is a contraction mapping for each $i=1,2,3$, then we have $P_{\Omega_{i}} f_{i}$ which is a contraction and also have

$$
P_{\Omega_{1}} f_{1} \circ P_{\Omega_{2}} f_{2} \circ P_{\Omega_{3}} f_{3}
$$

which is a contraction. Hence there exists a unique element $x^{*} \in H$ such that

$$
x^{*}=\left(P_{\Omega_{1}} f_{1} \circ P_{\Omega_{2}} f_{2} \circ P_{\Omega_{3}} f_{3}\right) x^{*} .
$$

Putting $z^{*}=P_{\Omega_{3}} f_{3}\left(x^{*}\right)$ and $y^{*}=P_{\Omega_{2}} f_{2}\left(z^{*}\right)$, then $z^{*} \in \Omega_{3}$, $y^{*} \in \Omega_{2}$, and $x^{*}=P_{\Omega_{1}} f_{1}\left(y^{*}\right)$.

Suppose that there is an element $(\hat{x}, \widehat{y}, \widehat{z}) \in \Omega_{1} \times \Omega_{2} \times \Omega_{3}$ such that the following three inequalities are satisfied:

$$
\begin{array}{ll}
\left\langle\widehat{x}-f_{1}(\widehat{y}), x-\widehat{x}\right\rangle \geq 0, & \forall x \in \Omega_{1}, \\
\left\langle\widehat{y}-f_{2}(\widehat{z}), y-\widehat{y}\right\rangle \geq 0, & \forall y \in \Omega_{2}, \\
\left\langle\widehat{z}-f_{3}(\widehat{x}), z-\widehat{z}\right\rangle \geq 0, & \forall z \in \Omega_{3} .
\end{array}
$$


Then

$$
\begin{aligned}
& \widehat{x}=P_{\Omega_{1}} f_{1}(\widehat{y}), \\
& \widehat{y}=P_{\Omega_{2}} f_{2}(\widehat{z}), \\
& \widehat{z}=P_{\Omega_{3}} f_{3}(\widehat{x}) .
\end{aligned}
$$

Therefore

$$
\widehat{x}=\left(P_{\Omega_{1}} f_{1} \circ P_{\Omega_{2}} f_{2} \circ P_{\Omega_{3}} f_{3}\right) \hat{x} .
$$

This implies that $\widehat{x}=x^{*}, \widehat{y}=y^{*}$, and $\widehat{z}=z^{*}$. This completes the proof.

\subsection{A Convergence Theorem}

Theorem 11. Let $A_{i}, M_{i}, \Omega_{i}, K_{i}$, and $K_{i, \beta}$ satisfy conditions (C1) and (C2), and let $f_{i}: H \rightarrow H$ be contractions with a contractive constant $h_{i} \in(0,1)$, for all $i=1,2,3$. Let $\left\{x_{n}\right\}$, $\left\{y_{n}\right\}$, and $\left\{z_{n}\right\}$ be three sequences defined by

$$
\begin{aligned}
& x_{0}, y_{0}, z_{0} \in H, \\
& x_{n+1}=\left(1-\alpha_{n}\right) K_{1, \beta} x_{n}+\alpha_{n} f_{1}\left(K_{2, \beta} y_{n}\right), \\
& y_{n+1}=\left(1-\alpha_{n}\right) K_{2, \beta} y_{n}+\alpha_{n} f_{2}\left(K_{3, \beta} z_{n}\right), \\
& z_{n+1}=\left(1-\alpha_{n}\right) K_{3, \beta} z_{n}+\alpha_{n} f_{3}\left(K_{1, \beta} x_{n}\right), \\
& n=0,1,2, \ldots,
\end{aligned}
$$

where $\left\{\alpha_{n}\right\}$ is a sequence in $(0,1)$ satisfying $\alpha_{n} \rightarrow 0$ and $\sum_{n=0}^{\infty} \alpha_{n}=\infty$. Then the sequences $\left\{x_{n}\right\},\left\{y_{n}\right\}$, and $\left\{z_{n}\right\}$ generated to be (42) converge to $x^{*}, y^{*}$, and $z^{*}$, respectively, where $\left(x^{*}, y^{*}, z^{*}\right)$ is the unique element in $\Omega_{1} \times \Omega_{2} \times \Omega_{3}$ verifying (36).

Proof. (i) First we prove that sequences $\left\{x_{n}\right\},\left\{y_{n}\right\}$, and $\left\{z_{n}\right\}$ are bounded.

From Lemma 9, it follow that $K_{i, \beta}$ is strongly quasinonexpansive and $F\left(K_{i, \beta}\right)=F\left(K_{i}\right)=\Omega_{i}$ for each $i=1,2$, 3. Since $f_{i}$ is contraction with the coefficient $h_{i}$ for each $i=1,2,3$ and $x^{*} \in F\left(K_{1, \beta}\right), y^{*} \in F\left(K_{2, \beta}\right)$, and $z^{*} \in F\left(K_{3, \beta}\right)$, it follows that

$$
\begin{aligned}
\left\|x_{n+1}-x^{*}\right\| \leq & \left(1-\alpha_{n}\right)\left\|K_{1, \beta} x_{n}-x^{*}\right\| \\
& +\alpha_{n}\left\|f_{1}\left(K_{2, \beta} y_{n}\right)-x^{*}\right\| \\
\leq & \left(1-\alpha_{n}\right)\left\|x_{n}-x^{*}\right\| \\
& +\alpha_{n}\left\|f_{1}\left(K_{2, \beta} y_{n}\right)-f_{1}\left(y^{*}\right)\right\| \\
& +\alpha_{n}\left\|f_{1}\left(y^{*}\right)-x^{*}\right\| \\
\leq & \left(1-\alpha_{n}\right)\left\|x_{n}-x^{*}\right\|+\alpha_{n} h_{1}\left\|K_{2, \beta} y_{n}-y^{*}\right\| \\
& +\alpha_{n}\left\|f_{1}\left(y^{*}\right)-x^{*}\right\| \\
\leq & \left(1-\alpha_{n}\right)\left\|x_{n}-x^{*}\right\|+\alpha_{n} h_{1}\left\|y_{n}-y^{*}\right\| \\
& +\alpha_{n}\left\|f_{1}\left(y^{*}\right)-x^{*}\right\| \\
\leq & \left(1-\alpha_{n}\right)\left\|x_{n}-x^{*}\right\|+\alpha_{n} h\left\|y_{n}-y^{*}\right\| \\
& +\alpha_{n}\left\|f_{1}\left(y^{*}\right)-x^{*}\right\|,
\end{aligned}
$$

where $h=\max \left\{h_{1}, h_{2}, h_{3}\right\}$. Similarly, we can also compute that

$$
\begin{aligned}
\left\|y_{n+1}-y^{*}\right\| \leq & \left(1-\alpha_{n}\right)\left\|y_{n}-y^{*}\right\|+\alpha_{n} h\left\|z_{n}-z^{*}\right\| \\
& +\alpha_{n}\left\|f_{2}\left(z^{*}\right)-y^{*}\right\|, \\
\left\|z_{n+1}-z^{*}\right\| \leq & \left(1-\alpha_{n}\right)\left\|z_{n}-z^{*}\right\|+\alpha_{n} h\left\|x_{n}-x^{*}\right\| \\
& +\alpha_{n}\left\|f_{3}\left(x^{*}\right)-z^{*}\right\| .
\end{aligned}
$$

This implies that

$$
\begin{aligned}
& \left\|x_{n+1}-x^{*}\right\|+\left\|y_{n+1}-y^{*}\right\|+\left\|z_{n+1}-z^{*}\right\| \\
& \leq\left(1-\alpha_{n}(1-h)\right)\left[\left\|x_{n}-x^{*}\right\|+\left\|y_{n}-y^{*}\right\|+\left\|z_{n}-z^{*}\right\|\right] \\
& +\alpha_{n}(1-h) \\
& \quad \times \frac{\left\|f_{1}\left(y^{*}\right)-x^{*}\right\|+\left\|f_{2}\left(z^{*}\right)-y^{*}\right\|+\left\|f_{3}\left(x^{*}\right)-z^{*}\right\|}{1-h} \\
& \leq \max \left\{\left\|x_{n}-x^{*}\right\|+\left\|y_{n}-y^{*}\right\|+\left\|z_{n}-z^{*}\right\|,\right. \\
& \left(\left\|f_{1}\left(y^{*}\right)-x^{*}\right\|+\left\|f_{2}\left(z^{*}\right)-y^{*}\right\|\right. \\
& \left.\left.+\left\|f_{3}\left(x^{*}\right)-z^{*}\right\|\right) \times(1-h)^{-1}\right\} .
\end{aligned}
$$

By induction, we have

$$
\begin{gathered}
\left\|x_{n+1}-x^{*}\right\|+\left\|y_{n+1}-y^{*}\right\|+\left\|z_{n+1}-z^{*}\right\| \\
\leq \max \left\{\left\|x_{0}-x^{*}\right\|+\left\|y_{0}-y^{*}\right\|+\left\|z_{0}-z^{*}\right\|,\right. \\
\left(\left\|f_{1}\left(y^{*}\right)-x^{*}\right\|+\left\|f_{2}\left(z^{*}\right)-y^{*}\right\|\right. \\
\left.\left.+\left\|f_{3}\left(x^{*}\right)-z^{*}\right\|\right) \times(1-h)^{-1}\right\},
\end{gathered}
$$

for all $n \geq 1$.

Hence $\left\{x_{n}\right\},\left\{y_{n}\right\}$, and $\left\{z_{n}\right\}$ are bounded. Consequently, $\left\{K_{1, \beta} x_{n}\right\},\left\{K_{2, \beta} y_{n}\right\}$, and $\left\{K_{3, \beta} z_{n}\right\}$ are bounded.

(ii) Next we prove that for each $n \geq 1$ the following inequality holds:

$$
\begin{aligned}
& \left\|x_{n+1}-x^{*}\right\|^{2}+\left\|y_{n+1}-y^{*}\right\|^{2}+\left\|z_{n+1}-z^{*}\right\|^{2} \\
& \leq\left(1-\alpha_{n}\right)^{2}\left(\left\|x_{n}-x^{*}\right\|^{2}+\left\|y_{n}-y^{*}\right\|^{2}+\left\|z_{n}-z^{*}\right\|^{2}\right) \\
& +2 \alpha_{n} h\left(\left\|x_{n+1}-x^{*}\right\|\left\|y_{n}-y^{*}\right\|+\left\|y_{n+1}-y^{*}\right\|\right. \\
& \left.\times\left\|z_{n}-z^{*}\right\|+\left\|z_{n+1}-z^{*}\right\|\left\|x_{n}-x^{*}\right\|\right) \\
& +2 \alpha_{n}\left(\left\langle f_{1}\left(y^{*}\right)-x^{*}, x_{n+1}-x^{*}\right\rangle\right. \\
& +\left\langle f_{2}\left(z^{*}\right)-y^{*}, y_{n+1}-y^{*}\right\rangle \\
& \left.+\left\langle f_{3}\left(x^{*}\right)-z^{*}, z_{n+1}-z^{*}\right\rangle\right)
\end{aligned}
$$


From (42) and Lemma 6, we have

$$
\begin{aligned}
&\left\|x_{n+1}-x^{*}\right\|^{2} \\
&=\left\|\left(1-\alpha_{n}\right)\left(K_{1, \beta} x_{n}-x^{*}\right)+\alpha_{n}\left(f_{1}\left(K_{2, \beta} y_{n}\right)-x^{*}\right)\right\|^{2} \\
& \leq\left\|\left(1-\alpha_{n}\right)\left(K_{1, \beta} x_{n}-x^{*}\right)\right\|^{2} \\
&+2 \alpha_{n}\left\langle f_{1}\left(K_{2, \beta} y_{n}\right)-x^{*}, x_{n+1}-x^{*}\right\rangle \\
&=\left(1-\alpha_{n}\right)^{2}\left\|K_{1, \beta} x_{n}-x^{*}\right\|^{2} \\
&+2 \alpha_{n}\left\langle f_{1}\left(K_{2, \beta} y_{n}\right)-f_{1}\left(y^{*}\right), x_{n+1}-x^{*}\right\rangle \\
&+2 \alpha_{n}\left\langle f_{1}\left(y^{*}\right)-x^{*}, x_{n+1}-x^{*}\right\rangle \\
& \leq\left(1-\alpha_{n}\right)^{2}\left\|x_{n}-x^{*}\right\|^{2}+2 \alpha_{n}\left\|f_{1}\left(K_{2, \beta} y_{n}\right)-f_{1}\left(y^{*}\right)\right\| \\
& \times\left\|x_{n+1}-x^{*}\right\|+2 \alpha_{n}\left\langle f_{1}\left(y^{*}\right)-x^{*}, x_{n+1}-x^{*}\right\rangle \\
& \leq\left(1-\alpha_{n}\right)^{2}\left\|x_{n}-x^{*}\right\|^{2}+2 \alpha_{n} h_{1}\left\|K_{2, \beta} y_{n}-y^{*}\right\| \\
& \times\left\|x_{n+1}-x^{*}\right\|+2 \alpha_{n}\left\langle f_{1}\left(y^{*}\right)-x^{*}, x_{n+1}-x^{*}\right\rangle \\
& \leq\left(1-\alpha_{n}\right)^{2}\left\|x_{n}-x^{*}\right\|^{2}+2 \alpha_{n} h\left\|y_{n}-y^{*}\right\|\left\|x_{n+1}-x^{*}\right\| \\
&+2 \alpha_{n}\left\langle f_{1}\left(y^{*}\right)-x^{*}, x_{n+1}-x^{*}\right\rangle . \\
&
\end{aligned}
$$

Similarly, we can also prove that

$$
\begin{aligned}
\left\|y_{n+1}-y^{*}\right\|^{2} \leq & \left(1-\alpha_{n}\right)^{2}\left\|y_{n}-y^{*}\right\|^{2} \\
& +2 \alpha_{n} h\left\|z_{n}-z^{*}\right\|\left\|y_{n+1}-y^{*}\right\| \\
& +2 \alpha_{n}\left\langle f_{2}\left(z^{*}\right)-y^{*}, y_{n+1}-y^{*}\right\rangle, \\
\left\|z_{n+1}-z^{*}\right\|^{2} \leq & \left(1-\alpha_{n}\right)^{2}\left\|z_{n}-z^{*}\right\|^{2} \\
& +2 \alpha_{n} h\left\|x_{n}-x^{*}\right\|\left\|z_{n+1}-z^{*}\right\| \\
& +2 \alpha_{n}\left\langle f_{3}\left(x^{*}\right)-z^{*}, z_{n+1}-z^{*}\right\rangle .
\end{aligned}
$$

Adding up inequalities (48) and (49), inequality (47) is proved.

(iii) Next, we prove that if there exists a subsequence $\left\{n_{k}\right\} \subset\{n\}$ such that

$$
\begin{aligned}
\liminf _{k \rightarrow \infty}\{ & \left(\left\|x_{n_{k}+1}-x^{*}\right\|^{2}+\left\|y_{n_{k}+1}-y^{*}\right\|^{2}+\left\|z_{n_{k}+1}-z^{*}\right\|^{2}\right) \\
& \left.-\left(\left\|x_{n_{k}}-x^{*}\right\|^{2}+\left\|y_{n_{k}}-y^{*}\right\|^{2}+\left\|z_{n_{k}}-z^{*}\right\|^{2}\right)\right\} \geq 0,
\end{aligned}
$$

then

$$
\begin{aligned}
\limsup _{k \rightarrow \infty}\{ & \left\langle f_{1}\left(y^{*}\right)-x^{*}, x_{n_{k}+1}-x^{*}\right\rangle \\
& +\left\langle f_{2}\left(z^{*}\right)-y^{*}, y_{n_{k}+1}-y^{*}\right\rangle \\
& \left.+\left\langle f_{3}\left(x^{*}\right)-z^{*}, z_{n_{k}+1}-z^{*}\right\rangle\right\} \leq 0 .
\end{aligned}
$$

Since the norm $\|\cdot\|^{2}$ is convex and $\lim _{n \rightarrow \infty} \alpha_{n}=0$, by (42), we have

$$
\begin{aligned}
& 0 \leq \liminf _{k \rightarrow \infty}\left\{\left(\left\|x_{n_{k}+1}-x^{*}\right\|^{2}+\left\|y_{n_{k}+1}-y^{*}\right\|^{2}\right.\right. \\
& \left.+\left\|z_{n_{k}+1}-z^{*}\right\|^{2}\right) \\
& -\left(\left\|x_{n_{k}}-x^{*}\right\|^{2}+\left\|y_{n_{k}}-y^{*}\right\|^{2}\right. \\
& \left.\left.+\left\|z_{n_{k}}-z^{*}\right\|^{2}\right)\right\} \\
& \leq \liminf _{k \rightarrow \infty}\left\{\left(1-\alpha_{n_{k}}\right)\left\|K_{1, \beta} x_{n_{k}}-x^{*}\right\|^{2}\right. \\
& +\alpha_{n_{k}}\left\|f_{1}\left(K_{2, \beta} y_{n_{k}}\right)-x^{*}\right\|^{2} \\
& +\left(1-\alpha_{n_{k}}\right)\left\|K_{2, \beta} y_{n_{k}}-y^{*}\right\|^{2} \\
& +\alpha_{n_{k}}\left\|f_{2}\left(K_{3, \beta} z_{n_{k}}\right)-y^{*}\right\|^{2} \\
& +\left(1-\alpha_{n_{k}}\right)\left\|K_{3, \beta} z_{n_{k}}-z^{*}\right\|^{2} \\
& +\alpha_{n_{k}}\left\|f_{3}\left(K_{1, \beta} x_{n_{k}}\right)-z^{*}\right\|^{2} \\
& -\left(\left\|x_{n_{k}}-x^{*}\right\|^{2}+\left\|y_{n_{k}}-y^{*}\right\|^{2}\right. \\
& \left.\left.+\left\|z_{n_{k}}-z^{*}\right\|^{2}\right)\right\} \\
& =\liminf _{k \rightarrow \infty}\left\{\left(\left\|K_{1, \beta} x_{n_{k}}-x^{*}\right\|^{2}-\left\|x_{n_{k}}-x^{*}\right\|^{2}\right)\right. \\
& +\left(\left\|K_{2, \beta} y_{n_{k}}-y^{*}\right\|^{2}-\left\|y_{n_{k}}-y^{*}\right\|^{2}\right) \\
& \left.+\left(\left\|K_{3, \beta} z_{n_{k}}-z^{*}\right\|^{2}-\left\|z_{n_{k}}-z^{*}\right\|^{2}\right)\right\} \\
& \leq \limsup _{k \rightarrow \infty}\left\{\left(\left\|K_{1, \beta} x_{n_{k}}-x^{*}\right\|^{2}-\left\|x_{n_{k}}-x^{*}\right\|^{2}\right)\right. \\
& +\left(\left\|K_{2, \beta} y_{n_{k}}-y^{*}\right\|^{2}-\left\|y_{n_{k}}-y^{*}\right\|^{2}\right) \\
& \left.+\left(\left\|K_{3, \beta} z_{n_{k}}-z^{*}\right\|^{2}-\left\|z_{n_{k}}-z^{*}\right\|^{2}\right)\right\}
\end{aligned}
$$

$\leq 0$.

This implies that

$$
\begin{aligned}
& \lim _{k \rightarrow \infty}\left(\left\|K_{1, \beta} x_{n_{k}}-x^{*}\right\|^{2}-\left\|x_{n_{k}}-x^{*}\right\|^{2}\right) \\
& =\lim _{k \rightarrow \infty}\left(\left\|K_{2, \beta} y_{n_{k}}-y^{*}\right\|^{2}-\left\|y_{n_{k}}-y^{*}\right\|^{2}\right) \\
& =\lim _{k \rightarrow \infty}\left(\left\|K_{3, \beta} z_{n_{k}}-z^{*}\right\|^{2}-\left\|z_{n_{k}}-z^{*}\right\|^{2}\right)=0 .
\end{aligned}
$$


Since the sequences $\left\{\left\|K_{1, \beta} x_{n_{k}}-x^{*}\right\|+\left\|x_{n_{k}}-x^{*}\right\|\right\},\left\{\| K_{2, \beta} y_{n_{k}}-\right.$ $\left.y^{*}\|+\| y_{n_{k}}-y^{*} \|\right\}$, and $\left\{\left\|K_{3, \beta} z_{n_{k}}-z^{*}\right\|+\left\|z_{n_{k}}-z^{*}\right\|\right\}$ are bounded, we have

$$
\begin{aligned}
& \lim _{k \rightarrow \infty}\left(\left\|K_{1, \beta} x_{n_{k}}-x^{*}\right\|-\left\|x_{n_{k}}-x^{*}\right\|\right) \\
& \quad=\lim _{k \rightarrow \infty}\left(\left\|K_{2, \beta} y_{n_{k}}-y^{*}\right\|-\left\|y_{n_{k}}-y^{*}\right\|\right) \\
& \quad=\lim _{k \rightarrow \infty}\left(\left\|K_{3, \beta} z_{n_{k}}-z^{*}\right\|-\left\|z_{n_{k}}-z^{*}\right\|\right)=0 .
\end{aligned}
$$

By Lemma $9, K_{1, \beta}, K_{2, \beta}$, and $K_{3, \beta}$ are strongly quasinonexpansive. We have

$$
\begin{gathered}
K_{1, \beta} x_{n_{k}}-x_{n_{k}} \longrightarrow 0, \quad K_{2, \beta} y_{n_{k}}-y_{n_{k}} \longrightarrow 0 \\
K_{3, \beta} z_{n_{k}}-z_{n_{k}} \longrightarrow 0 .
\end{gathered}
$$

Consequently, we obtain that

$$
\begin{gathered}
x_{n_{k}}-x_{n_{k}+1} \longrightarrow 0, \quad y_{n_{k}}-y_{n_{k}+1} \longrightarrow 0, \\
z_{n_{k}}-z_{n_{k}+1} \longrightarrow 0 .
\end{gathered}
$$

It follows from the boundedness of $\left\{x_{n_{k}}\right\}$ and $H$ which is reflexive that there exists a subsequence $\left\{x_{n_{k_{l}}}\right\}$ of $\left\{x_{n_{k}}\right\}$ such that $x_{n_{k_{l}}} \rightarrow p$ and

$$
\begin{aligned}
\lim _{l \rightarrow \infty} & \left\langle f_{1}\left(y^{*}\right)-x^{*}, x_{n_{k_{l}}}-x^{*}\right\rangle \\
= & \limsup _{k \rightarrow \infty}\left\langle f_{1}\left(y^{*}\right)-x^{*}, x_{n_{k}}-x^{*}\right\rangle \\
= & \limsup _{k \rightarrow \infty}\left\langle f_{1}\left(y^{*}\right)-x^{*}, x_{n_{k}+1}-x^{*}\right\rangle .
\end{aligned}
$$

By Lemma 9, $I-K_{1, \beta}$ is demiclosed at zero, and so $p \in$ $F\left(K_{1, \beta}\right)=\Omega_{1}$. Hence from (36) we have

$$
\begin{aligned}
& \lim _{l \rightarrow \infty}\left\langle f_{1}\left(y^{*}\right)-x^{*}, x_{n_{k_{l}}}-x^{*}\right\rangle \\
& =\left\langle f_{1}\left(y^{*}\right)-x^{*}, p-x^{*}\right\rangle \leq 0 .
\end{aligned}
$$

Therefore

$$
\begin{aligned}
& \limsup _{k \rightarrow \infty}\left\langle f_{1}\left(y^{*}\right)-x^{*}, x_{n_{k}+1}-x^{*}\right\rangle \\
& \quad=\lim _{l \rightarrow \infty}\left\langle f_{1}\left(y^{*}\right)-x^{*}, x_{n_{k_{l}}}-x^{*}\right\rangle \leq 0 .
\end{aligned}
$$

Similarly, we can also prove that

$$
\begin{aligned}
& \limsup _{k \rightarrow \infty}\left\langle f_{2}\left(z^{*}\right)-y^{*}, y_{n_{k}+1}-y^{*}\right\rangle \leq 0, \\
& \limsup _{k \rightarrow \infty}\left\langle f_{3}\left(x^{*}\right)-z^{*}, z_{n_{k}+1}-z^{*}\right\rangle \leq 0 .
\end{aligned}
$$

Hence, we have the desired inequality.

(iv) Finally, we prove that the sequences $\left\{x_{n}\right\},\left\{y_{n}\right\}$, and $\left\{z_{n}\right\}$ generated to be (42) converge to $x^{*}, y^{*}$, and $z^{*}$, respectively.
It is clear that

$$
\begin{gathered}
\left\|x_{n+1}-x^{*}\right\|\left\|y_{n}-y^{*}\right\|+\left\|y_{n+1}-y^{*}\right\|\left\|z_{n}-z^{*}\right\| \\
+\left\|z_{n+1}-z^{*}\right\|\left\|x_{n}-x^{*}\right\| \\
\leq\left(\left\|x_{n}-x^{*}\right\|^{2}+\left\|y_{n}-y^{*}\right\|^{2}+\left\|z_{n}-z^{*}\right\|^{2}\right)^{1 / 2} \\
\times\left(\left\|x_{n+1}-x^{*}\right\|^{2}+\left\|y_{n+1}-y^{*}\right\|^{2}\right. \\
\left.+\left\|z_{n+1}-z^{*}\right\|^{2}\right)^{1 / 2} .
\end{gathered}
$$

Substituting (61) into (47), we have

$$
\begin{gathered}
\left\|x_{n+1}-x^{*}\right\|^{2}+\left\|y_{n+1}-y^{*}\right\|^{2}+\left\|z_{n+1}-z^{*}\right\|^{2} \\
\leq\left(1-\alpha_{n}\right)^{2}\left(\left\|x_{n}-x^{*}\right\|^{2}+\left\|y_{n}-y^{*}\right\|^{2}+\left\|z_{n}-z^{*}\right\|^{2}\right) \\
+2 \alpha_{n} h\left\{\left(\left\|x_{n}-x^{*}\right\|^{2}+\left\|y_{n}-y^{*}\right\|^{2}\right.\right. \\
\left.+\left\|z_{n}-z^{*}\right\|^{2}\right)^{1 / 2} \\
\times\left(\left\|x_{n+1}-x^{*}\right\|^{2}+\left\|y_{n+1}-y^{*}\right\|^{2}\right. \\
\left.\left.+\left\|z_{n+1}-z^{*}\right\|^{2}\right)^{1 / 2}\right\} \\
+2 \alpha_{n}\left(\left\langle f_{1}\left(y^{*}\right)-x^{*}, x_{n+1}-x^{*}\right\rangle\right. \\
+\left\langle f_{2}\left(z^{*}\right)-y^{*}, y_{n+1}-y^{*}\right\rangle \\
\left.+\left\langle f_{3}\left(x^{*}\right)-z^{*}, z_{n+1}-z^{*}\right\rangle\right) .
\end{gathered}
$$

Set

$$
\begin{aligned}
a_{n}:=\| x_{n}- & x^{*}\left\|^{2}+\right\| y_{n}-y^{*}\left\|^{2}+\right\| z_{n}-z^{*} \|^{2}, \\
b_{n}:=2( & \left\langle f_{1}\left(y^{*}\right)-x^{*}, x_{n+1}-x^{*}\right\rangle \\
& +\left\langle f_{2}\left(z^{*}\right)-y^{*}, y_{n+1}-y^{*}\right\rangle \\
+ & \left.\left\langle f_{3}\left(x^{*}\right)-z^{*}, z_{n+1}-z^{*}\right\rangle\right) .
\end{aligned}
$$

Then, we have the following statements.

(i) From (i), $\left\{a_{n}\right\}$ is bounded sequence.

(ii) From (62), $a_{n+1} \leq\left(1-\alpha_{n}\right)^{2} a_{n}+2 \alpha_{n} h \sqrt{a_{n}} \sqrt{a_{n+1}}+\alpha_{n} b_{n}$, for all $n \geq 1$.

(iii) From (iii), whenever $\left\{a_{n_{k}}\right\}$ is a subsequence of $\left\{a_{n}\right\}$ satisfying

$$
\liminf _{k \rightarrow \infty}\left(a_{n_{k}+1}-a_{n_{k}}\right) \geq 0,
$$

it follows that lim $\sup _{k \rightarrow \infty} b_{n_{k}} \leq 0$.

By Lemma 8, we have

$$
\lim _{n \rightarrow \infty}\left(\left\|x_{n}-x^{*}\right\|^{2}+\left\|y_{n}-y^{*}\right\|^{2}+\left\|z_{n}-z^{*}\right\|^{2}\right)=0 .
$$


Hence, we obtain that

$$
\lim _{n \rightarrow \infty}\left\|x_{n}-x^{*}\right\|=\lim _{n \rightarrow \infty}\left\|y_{n}-y^{*}\right\|=\lim _{n \rightarrow \infty}\left\|z_{n}-z^{*}\right\|=0 .
$$

This completes the proof.

3.3. Consequence Results. Using Theorem 11, we can prove the following results.

Theorem 12. Let $A_{i}, M_{i}, \Omega_{i}, K_{i}$, and $K_{i, \beta}$ satisfy conditions (C1) and (C2), and let $F: H \rightarrow H$ be a $\mu$-Lipschitzian and $r$-strongly monotone mapping. Let $\left\{x_{n}\right\},\left\{y_{n}\right\}$, and $\left\{z_{n}\right\}$ be three sequences defined by

$$
\begin{aligned}
& x_{0}, y_{0}, z_{0} \in H, \\
& x_{n+1}=\left(1-\alpha_{n}\right) K_{1, \beta} x_{n}+\alpha_{n} f_{1}\left(K_{2, \beta} y_{n}\right), \\
& y_{n+1}=\left(1-\alpha_{n}\right) K_{2, \beta} y_{n}+\alpha_{n} f_{2}\left(K_{3, \beta} z_{n}\right), \\
& z_{n+1}=\left(1-\alpha_{n}\right) K_{3, \beta} z_{n}+\alpha_{n} f_{3}\left(K_{1, \beta} x_{n}\right), \\
& n=0,1,2, \ldots,
\end{aligned}
$$

where $f_{1}:=I-\rho F, f_{2}:=I-\eta F, f_{3}:=I-\xi F$ with $\rho, \eta, \xi \in\left(0,2 r / \mu^{2}\right)$, and $\left\{\alpha_{n}\right\}$ is a sequence in $(0,1)$ satisfying $\alpha_{n} \rightarrow 0$ and $\sum_{n=0}^{\infty} \alpha_{n}=\infty$. Then the sequences $\left\{x_{n}\right\},\left\{y_{n}\right\}$, and $\left\{z_{n}\right\}$ converge to $x^{*}, y^{*}$, and $z^{*}$, respectively, where $\left(x^{*}, y^{*}, z^{*}\right)$ is the unique element in $\Omega_{1} \times \Omega_{2} \times \Omega_{3}$ such that the following three inequalities are satisfied:

$$
\begin{array}{ll}
\left\langle\rho F\left(y^{*}\right)+x^{*}-y^{*}, x-x^{*}\right\rangle \geq 0, & \forall x \in \Omega_{1}, \\
\left\langle\eta F\left(z^{*}\right)+y^{*}-z^{*}, y-y^{*}\right\rangle \geq 0, & \forall y \in \Omega_{2}, \\
\left\langle\xi F\left(x^{*}\right)+z^{*}-x^{*}, z-z^{*}\right\rangle \geq 0, & \forall z \in \Omega_{3} .
\end{array}
$$

Proof. It is easy to see that $f_{1}, f_{2}$, and $f_{3}$ are contraction mappings and all the conditions in Theorem 11 are satisfied. By Theorem 11, we have the sequences $\left\{x_{n}\right\},\left\{y_{n}\right\}$, and $\left\{z_{n}\right\}$ which converge to $\left(x^{*}, y^{*}, z^{*}\right) \in \Omega_{1} \times \Omega_{2} \times \Omega_{3}$ such that the following three inequalities are satisfied:

$$
\begin{array}{ll}
\left\langle x^{*}-f_{1}\left(y^{*}\right), x-x^{*}\right\rangle \geq 0, & \forall x \in \Omega_{1}, \\
\left\langle y^{*}-f_{2}\left(z^{*}\right), y-y^{*}\right\rangle \geq 0, & \forall y \in \Omega_{2}, \\
\left\langle z^{*}-f_{3}\left(x^{*}\right), z-z^{*}\right\rangle \geq 0, & \forall z \in \Omega_{3} .
\end{array}
$$

Substituting $f_{1}:=I-\rho F, f_{2}:=I-\eta F$, and $f_{3}:=I-\xi F$ into (69), we obtain that the sequences $\left\{x_{n}\right\},\left\{y_{n}\right\}$, and $\left\{z_{n}\right\}$ converge to $\left(x^{*}, y^{*}, z^{*}\right) \in \Omega_{1} \times \Omega_{2} \times \Omega_{3}$ such that the following three inequalities are satisfied:

$$
\begin{array}{ll}
\left\langle\rho F\left(y^{*}\right)+x^{*}-y^{*}, x-x^{*}\right\rangle \geq 0, & \forall x \in \Omega_{1}, \\
\left\langle\eta F\left(z^{*}\right)+y^{*}-z^{*}, y-y^{*}\right\rangle \geq 0, & \forall y \in \Omega_{2}, \\
\left\langle\xi F\left(x^{*}\right)+z^{*}-x^{*}, z-z^{*}\right\rangle \geq 0, & \forall z \in \Omega_{3} .
\end{array}
$$

This completes the proof
Setting $A_{1}=A_{2}=A_{3}$ in Theorem 11, we obtain the following corollary.

Corollary 13. Let $A_{1}, M_{1}, \Omega_{1}, K_{1}$, and $K_{1, \beta}$ satisfy conditions (C1) and (C2), and let $f_{i}: H \rightarrow H$ be contractions with a contractive constant $h_{i} \in(0,1)$, for all $i=1,2,3$. Let $\left\{x_{n}\right\}$, $\left\{y_{n}\right\}$, and $\left\{z_{n}\right\}$ be three sequences defined by

$$
\begin{aligned}
& x_{0}, y_{0}, z_{0} \in H, \\
& x_{n+1}=\left(1-\alpha_{n}\right) K_{1, \beta} x_{n}+\alpha_{n} f_{1}\left(K_{1, \beta} y_{n}\right), \\
& y_{n+1}=\left(1-\alpha_{n}\right) K_{1, \beta} y_{n}+\alpha_{n} f_{2}\left(K_{1, \beta} z_{n}\right), \\
& z_{n+1}=\left(1-\alpha_{n}\right) K_{1, \beta} z_{n}+\alpha_{n} f_{3}\left(K_{1, \beta} x_{n}\right), \\
& n=0,1,2, \ldots,
\end{aligned}
$$

where $\left\{\alpha_{n}\right\}$ is a sequence in $(0,1)$ satisfying $\alpha_{n} \rightarrow 0$ and $\sum_{n=0}^{\infty} \alpha_{n}=\infty$. Then the sequences $\left\{x_{n}\right\},\left\{y_{n}\right\}$, and $\left\{z_{n}\right\}$ generated to be (42) converge to $x^{*}, y^{*}$, and $z^{*}$, respectively, where $\left(x^{*}, y^{*}, z^{*}\right)$ is the unique element in $\Omega_{1} \times \Omega_{1} \times \Omega_{1}$ such that the following three inequalities are satisfied:

$$
\begin{aligned}
& \left\langle x^{*}-f_{1}\left(y^{*}\right), x-x^{*}\right\rangle \geq 0, \quad \forall x \in \Omega_{1}, \\
& \left\langle y^{*}-f_{2}\left(z^{*}\right), x-y^{*}\right\rangle \geq 0, \quad \forall x \in \Omega_{1}, \\
& \left\langle z^{*}-f_{3}\left(x^{*}\right), x-z^{*}\right\rangle \geq 0, \quad \forall x \in \Omega_{1} .
\end{aligned}
$$

Corollary 14. Let $A_{1}, M_{1}, \Omega, K_{1}$, and $K_{1, \beta}$ satisfy conditions (C1) and (C2), and let $F: H \rightarrow H$ be $\mu$-Lipschitzian and $r$ strongly monotone mapping. Let $\left\{x_{n}\right\},\left\{y_{n}\right\}$, and $\left\{z_{n}\right\}$ be three sequences defined by

$$
\begin{aligned}
& x_{0}, y_{0}, z_{0} \in H, \\
& x_{n+1}=\left(1-\alpha_{n}\right) K_{1, \beta} x_{n}+\alpha_{n} f_{1}\left(K_{1, \beta} y_{n}\right), \\
& y_{n+1}=\left(1-\alpha_{n}\right) K_{1, \beta} y_{n}+\alpha_{n} f_{2}\left(K_{1, \beta} z_{n}\right), \\
& z_{n+1}=\left(1-\alpha_{n}\right) K_{1, \beta} z_{n}+\alpha_{n} f_{3}\left(K_{1, \beta} x_{n}\right), \\
& n=0,1,2, \ldots,
\end{aligned}
$$

where $f_{1}:=I-\rho F, f_{2}:=I-\eta F, f_{3}:=I-\xi F$ with $\rho, \eta, \xi \in\left(0,2 r / \mu^{2}\right)$, and $\left\{\alpha_{n}\right\}$ is a sequence in $(0,1)$ satisfying $\alpha_{n} \rightarrow 0$ and $\sum_{n=0}^{\infty} \alpha_{n}=\infty$. Then the sequences $\left\{x_{n}\right\},\left\{y_{n}\right\}$, and $\left\{z_{n}\right\}$ converge to $x^{*}, y^{*}$, and $z^{*}$, respectively, where $\left(x^{*}, y^{*}, z^{*}\right)$ is the unique element in $\Omega_{1} \times \Omega_{1} \times \Omega_{1}$ such that the following three inequalities are satisfied:

$$
\begin{array}{ll}
\left\langle\rho F\left(y^{*}\right)+x^{*}-y^{*}, x-x^{*}\right\rangle \geq 0, & \forall x \in \Omega_{1}, \\
\left\langle\eta F\left(z^{*}\right)+y^{*}-z^{*}, x-y^{*}\right\rangle \geq 0, & \forall x \in \Omega_{1}, \\
\left\langle\xi F\left(x^{*}\right)+z^{*}-x^{*}, x-z^{*}\right\rangle \geq 0, & \forall x \in \Omega_{1} .
\end{array}
$$

Setting $A_{1}=A_{2}=A_{3}, f_{1}=f_{2}=f_{3}$, and $x_{0}=y_{0}=z_{0}$ in Theorem 11, we obtain the following corollary. 
Corollary 15. Let $A_{1}, M_{1}, \Omega_{1}, K_{1}$, and $K_{1, \beta}$ satisfy conditions (C1) and (C2), and let $f: H \rightarrow H$ be contractions with a contractive constant $h \in(0,1)$. Let $\left\{x_{n}\right\}$ be the sequences defined by

$$
\begin{aligned}
& x_{0} \in H, \\
& x_{n+1}=\left(1-\alpha_{n}\right) K_{1, \beta} x_{n}+\alpha_{n} f\left(K_{1, \beta} x_{n}\right), \\
& n=0,1,2, \ldots,
\end{aligned}
$$

where $\left\{\alpha_{n}\right\}$ is a sequence in $(0,1)$ satisfying $\alpha_{n} \rightarrow 0$ and $\sum_{n=0}^{\infty} \alpha_{n}=\infty$. Then the sequences $\left\{x_{n}\right\}$ converge to $x^{*} \in \Omega_{1}$ such that the following three inequalities are satisfied:

$$
\left\langle x^{*}-f_{1}\left(x^{*}\right), x-x^{*}\right\rangle \geq 0, \quad \forall x \in \Omega_{1} .
$$

Corollary 16. Let $A_{1}, M_{1}, \Omega_{1}, K_{1}$, and $K_{1, \beta}$ satisfy conditions (C1) and (C2), and let $F: H \rightarrow H$ be $\mu$-Lipschitzian and $r$ strongly monotone mapping. Let $\left\{x_{n}\right\}$ be the sequences defined by

$$
\begin{aligned}
& x_{0} \in H, \\
& x_{n+1}=\left(1-\alpha_{n}\right) K_{1, \beta} x_{n}+\alpha_{n}(I-\rho F)\left(K_{1, \beta} x_{n}\right), \\
& n=0,1,2, \ldots,
\end{aligned}
$$

where $\rho \in\left(0,2 r / \mu^{2}\right)$ and $\left\{\alpha_{n}\right\}$ is a sequence in $(0,1)$ satisfying $\alpha_{n} \rightarrow 0$ and $\sum_{n=0}^{\infty} \alpha_{n}=\infty$. Then the sequences $\left\{x_{n}\right\}$ converge to $x^{*} \in \Omega_{1}$ such that the following three inequalities are satisfied:

$$
\left\langle F\left(x^{*}\right), x-x^{*}\right\rangle \geq 0, \quad \forall x \in \Omega_{1} .
$$

\section{Conflict of Interests}

The authors declare that there is no conflict of interests regarding to the publication of this paper.

\section{Acknowledgment}

The authors would like to thank the National Research University Project of Thailand's Office of the Higher Education Commission for financial support (NRU no. 57000621).

\section{References}

[1] M. A. Noor and K. I. Noor, "Sensitivity analysis for quasivariational inclusions," Journal of Mathematical Analysis and Applications, vol. 236, no. 2, pp. 290-299, 1999.

[2] S. S. Chang, "Set-valued variational inclusions in Banach spaces," Journal of Mathematical Analysis and Applications, vol. 248, no. 2, pp. 438-454, 2000.

[3] S. S. Chang, "Existence and approximation of solutions of set-valued variational inclusions in Banach spaces," Nonlinear Analysis, vol. 47, pp. 583-594, 2001.

[4] Y. Yao, Y. J. Cho, and Y. C. Liou, "Iterative algorithms for hierarchical fixed points problems and variational inequalities," Mathematical and Computer Modelling, vol. 52, no. 9-10, pp. 1697-1705, 2010.
[5] A. Moudafi and P. Maingé, "Towards viscosity approximations of hierarchical fixed-point problems," Fixed Point Theory and Applications, vol. 2006, Article ID 95453, 10 pages, 2006.

[6] H.-K. Xu, "Viscosity method for hierarchical fixed point approach to variational inequalities," Taiwanese Journal of Mathematics, vol. 14, no. 2, pp. 463-478, 2010.

[7] F. Cianciaruso, V. Colao, L. Muglia, and H.-K. Xu, "On an implicit hierarchical fixed point approach to variational inequalities," Bulletin of the Australian Mathematical Society, vol. 80, no. 1, pp. 117-124, 2009.

[8] P. E. Maingé and A. Moudafi, "Strong convergence of an iterative method for hierarchical fixed-point problems," Pacific Journal of Optimization, vol. 3, no. 3, pp. 529-538, 2007.

[9] A. Moudafi, "Krasnoselski-Mann iteration for hierarchical fixed-point problems," Inverse Problems, vol. 23, no. 4, pp. 16351640, 2007.

[10] Y. Yao and Y.-C. Liou, "Weak and strong convergence of Krasnoselski-Mann iteration for hierarchical fixed point problems," Inverse Problems, vol. 24, no. 1, Article ID 015015, 2008.

[11] G. Marino, V. Colao, L. Muglia, and Y. Yao, "Krasnoselski-Mann iteration for hierarchical fixed points and equilibrium problem," Bulletin of the Australian Mathematical Society, vol. 79, no. 2, pp. 187-200, 2009.

[12] P. L. Combettes, "A block-iterative surrogate constraint splitting method for quadratic signal recovery," IEEE Transactions on Signal Processing, vol. 51, no. 7, pp. 1771-1782, 2003.

[13] H. Iiduka, "Fixed point optimization algorithm and its application to power control in CDMA data networks," Mathematical Programming, vol. 133, no. 1-2, pp. 227-242, 2012.

[14] K. Slavakis and I. Yamada, "Robust wideband beamforming by the hybrid steepest descent method," IEEE Transactions on Signal Processing, vol. 55, no. 9, pp. 4511-4522, 2007.

[15] S. S. Chang, J. K. Kim, H. W. Lee, and C. K. Chun, "On the hierarchical variational inclusion problems in Hilbert spaces," Fixed Point Theory and Applications, vol. 2013, article 179, 2013.

[16] Y. Li, "Improving strong convergence results for hierarchical optimization," Theoretical Mathematics \& Applications, vol. 3, no. 2, pp. 1-14, 2013.

[17] P. E. Maingé, "New approach to solving a system of variational inequalities and hierarchical problems," Journal of Optimization Theory and Applications, vol. 138, no. 3, pp. 459-477, 2008.

[18] R. Kraikaew and S. Saejung, "On Maingé approach for hierarchical optimization problems," Journal of Optimization Theory and Applications, vol. 154, no. 1, pp. 71-87, 2012.

[19] G. Kassay, J. Kolumbán, and Z. Páles, "Factorization of Minty and Stampacchia variational inequality systems," European Journal of Operational Research, vol. 143, no. 2, pp. 377-389, 2002.

[20] G. Kassay and J. Kolumbn, "System of multi-valued variational inequalities," Publicationes Mathematicae Debrecen, vol. 56, no. 1-2, pp. 185-195, 2000.

[21] R. U. Verma, "Projection methods, algorithms, and a new system of nonlinear variational inequalities," Computers \& Mathematics with Applications, vol. 41, no. 7-8, pp. 1025-1031, 2001.

[22] S. Zhang, J. H. W. Lee, and C. K. Chan, "Algorithms of common solutions to quasi variational inclusion and fixed point problems," Applied Mathematics and Mechanics, vol. 29, no. 5, pp. 571-581, 2008. 
[23] W. Takahashi, Introduction to Nonlinear and Convex Analysis, Yokohama Publishers, Yokohama, Japan, 2009.

[24] P. E. Maingé, “The viscosity approximation process for quasinonexpansive mappings in Hilbert spaces," Computers \& Mathematics with Applications, vol. 59, no. 1, pp. 74-79, 2010. 


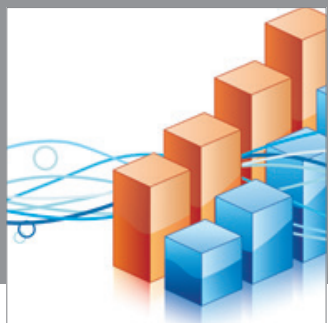

Advances in

Operations Research

mansans

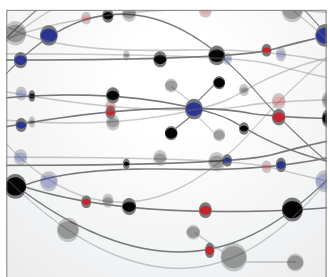

The Scientific World Journal
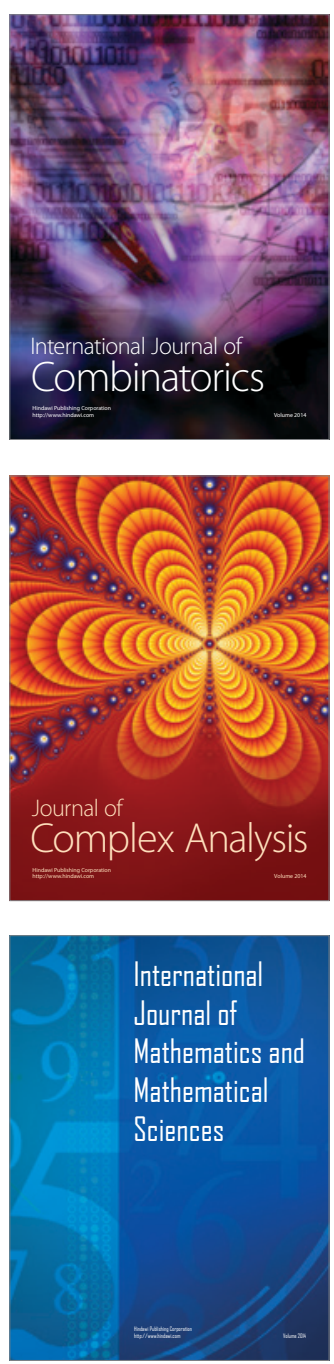
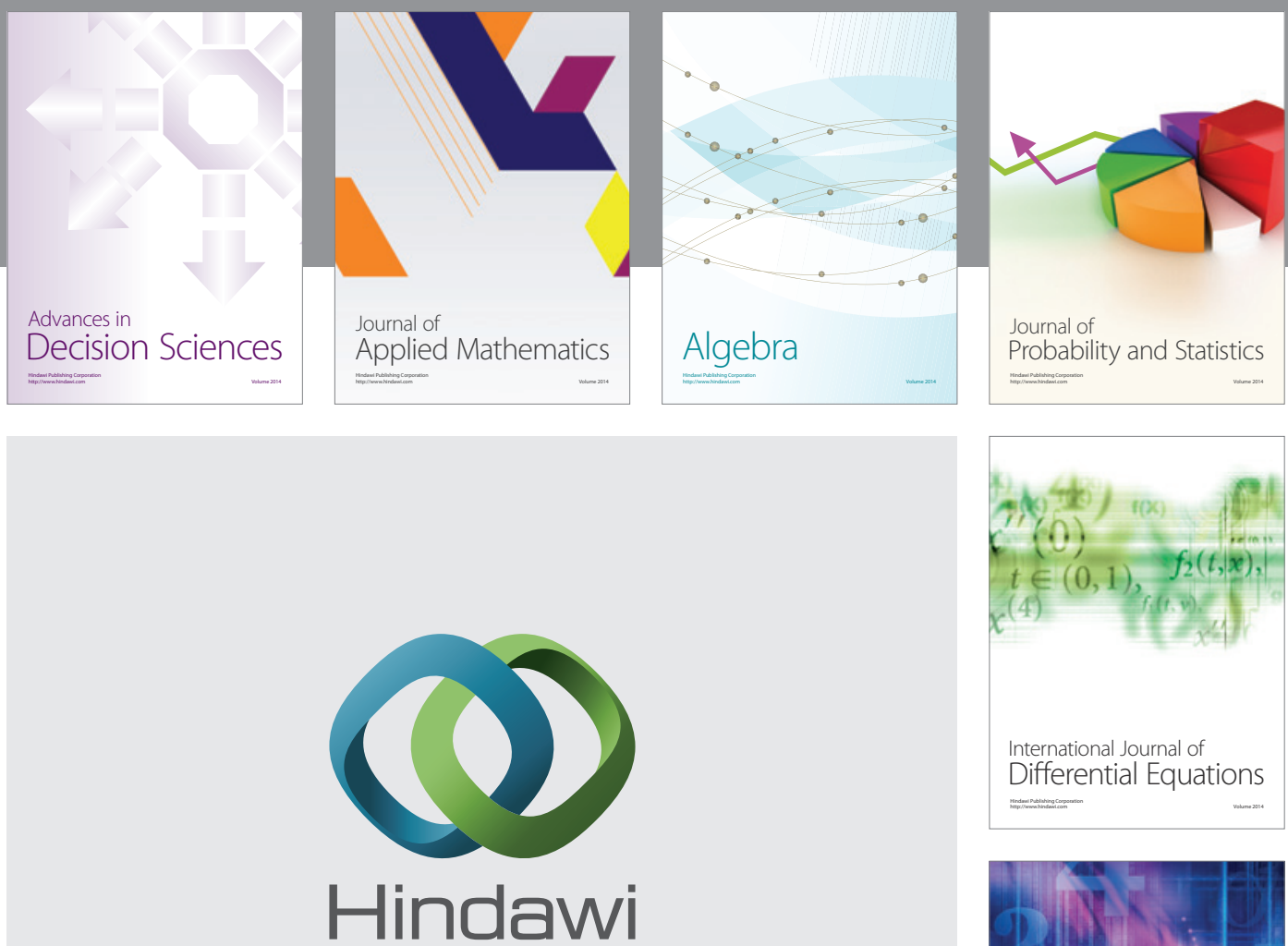

Submit your manuscripts at http://www.hindawi.com
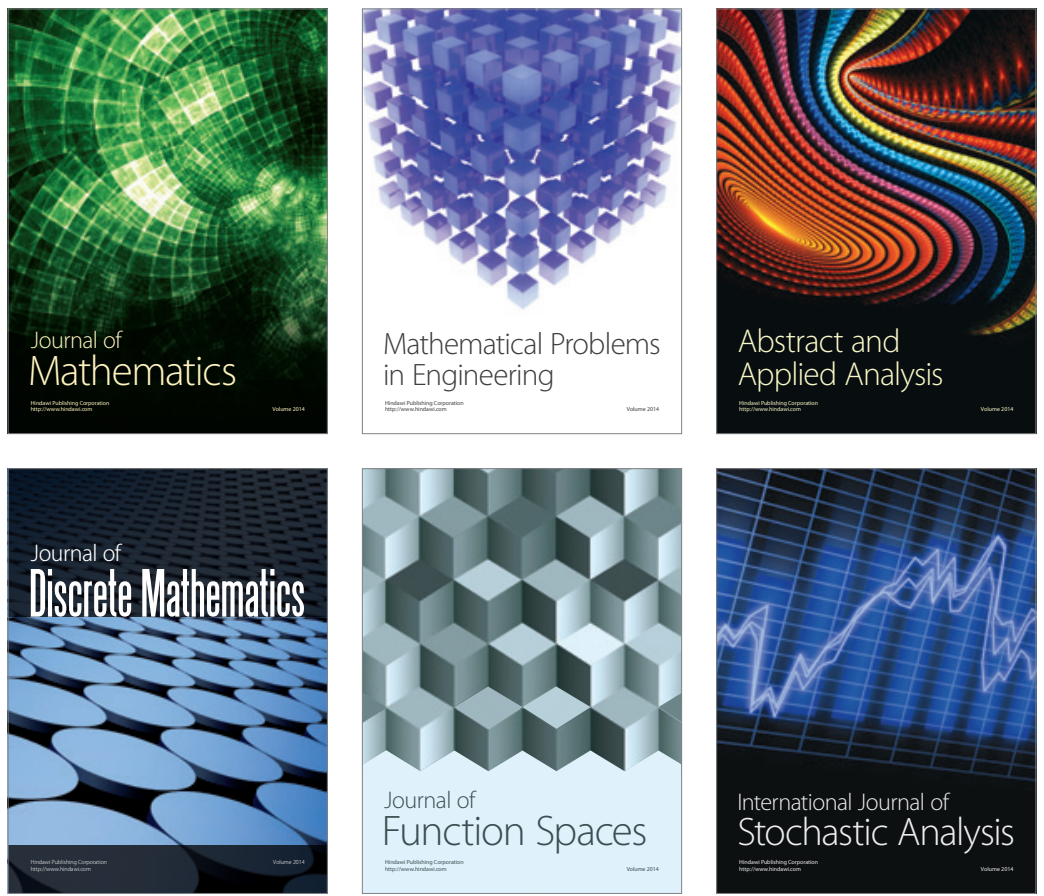

Journal of

Function Spaces

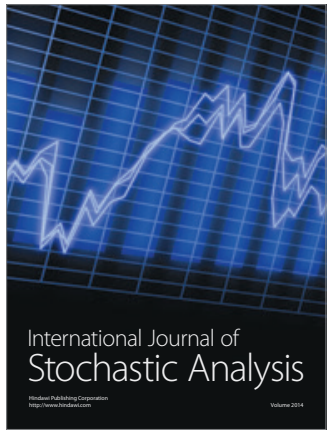

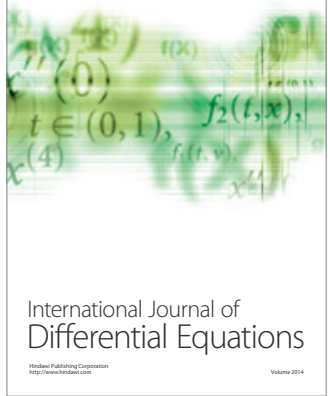
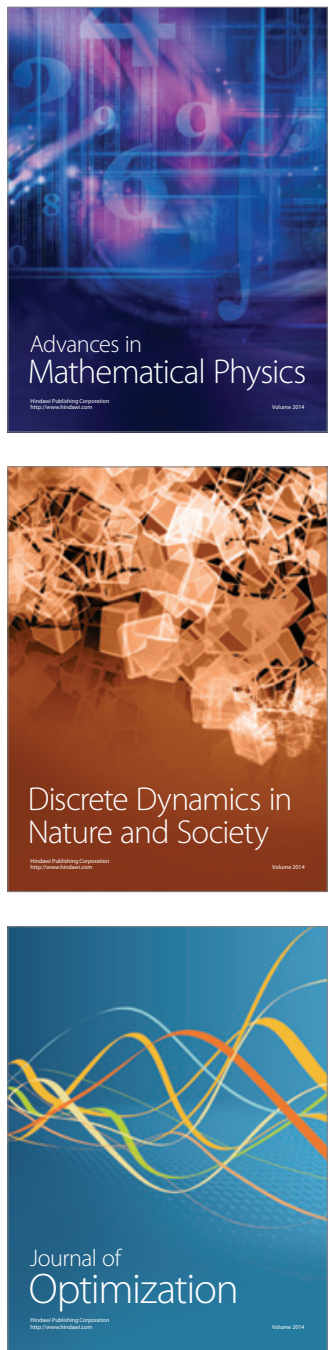